\title{
Factors Influencing School Education System Empowerment Using SWOT and Multiple Criteria Decision Making Approach
}

\author{
Negin Hatami ${ }^{1}$, Reza Soltani ${ }^{2}$ \\ 1- Department of industerial engineering, masjed soleiman Branch, \\ Islamic Azad University, masjed soleiman, Iran \\ 2-* Department of industerial engineering, masjed soleiman Branch, \\ Islamic Azad University, masjed soleiman, Iran. \\ Email: re.soltane@gmail.com
}

\begin{abstract}
The purpose of this research is investigating the impact of different factors on human resource empowerment. In terms of purpose, this research is applicable and in terms of research method is a descriptive-correlational type that library method used to collect the data needed to compile the research background and its theoretical foundations. The statistical population of this study is all school staff of Masjed Soleiman city, The sample for this study was 721 individuals from Morgan table which was taken 17 individuals for more convenience and validity. To collect data, the Spreitzer Empowerment Questionnaire and the researcher-made questionnaire were used. Factors Affecting the Empowerment of Staff were evaluated on the subjects. In this method, according to the extracted data of the questionnaire the TOPSIS method was used to rank the SWOT factors.The results indicate that SO strategy is the most preferred strategy among the other strategies and it was suggested to use strategic human resource management in planning for medium and long term periods and to increase motivational programs at Masjed Soleiman education level, especially at staff level. In this study, 4 hypotheses were investigated. Data analysis showed that according to the values obtained from the statistical data, all the research hypotheses confirmed and by using Topsis method was determined that the most effective factor on staff empowerment is education. And the performance measurement has the least impact on staff empowerment.In addition, data from t-test showed that gender and marital status had no impact on staff empowerment.
\end{abstract}

Keywords: Human resource Empowerment, Empowerment Factors, SWOT Factors.

Introduction:

Employee empowerment as a theoretical concept has a major impact on organizational effectiveness and organizational management and creativity. Thomas and Velthouse (1990) believe that empowered staff have more flexibility in controlling and performing tasks. They start new tasks in response to problems and opportunities and remove the barriers, as a result, their motivation is strengthened in dealing with problems. Empowerment has a vague and different concept and different people have different perceptions based on their own characteristics. This concept first attracted the attention of many scholars for the first time in the 1990s. Staff empowerment results include improved job satisfaction and customer satisfaction. Successful implementation of empowerment requires changing organizational culture. Empowerment as a subjective concept has a significant impact on organizational productivity and its effectiveness, so, employees are more flexible in controlling and performing their duties. Education is the most important institution in today's society that is humanizer and its complement. Paying attention to all the elements of education, including their human resources, their satisfaction as well as taking steps to empower them is one of the most valuable strategies and effective measures in education and its valuable evolution. The evolution of the education system must be accompanied by creativity, creating a healthy competitive environment and this is very effective in the light of human resource empowerment. In order to increase the productivity and job satisfaction of employees, it should be identified effective needs and criteria in their ability and motivation. And by creating a creative, joyful environment for a dynamic organization. and outlined important policies to improve this goal, Including identifying opportunities, strengths, and eliminating stressors and threats can further enhance the effectiveness and efficiency of education. Employee empowerment is a set of systems, methods and actions that are developed through the capability and competence of individuals to improve the productivity and growth and growth of the organization and human resources. The four most effective factors in empowering employees are the knowledge and skill, trust, communication and motivation that we process to them. 


\section{1-2-Problem Statement}

Today most organizations have to recognize their internal capabilities and abilities, repair weaknesses and strengthen their strengths to deal with environmental threats and seize opportunities. Denison (quotes from Yilmaz and Ergun 2008) has identified four important cultural characteristics, including conflict, accordance, adaptability and mission, as contradictions which affect modern organizations for effective performance, on the other hand, empowerment refers to the move from the hierarchical decision-making system of managers to the lowering hierarchical system of control and decision-making by lower levels;

As Sborne and Gaebler (quotes from Shellton 2002 ) believe that the best way to reduce bureaucracy is emphasizing on customer demand, rather than management demand and through staff empowerment.According to Jafari Ghushaji,( quotes from Moghimi, Mahram, Saeidi Rezvani and Agha Mohammadian, 1387) organizations should not wait for the wave, but should be the source of the wave and revolution and strive for their improvement.The rapid changes, technological advances and open and hidden competition in the world even more revealed the importance of empowerment. Empowerment is a pioneering and effective technology that provides strategic advantage for organizations and make opportunity personnel and is a tool for groups to participate in the organization's success and failure.Personnel empowerment is one of the effective tools for increasing personnel productivity and optimizing the use of individual and team capacities and abilities.

Along with organizational goals, organizations are affected by factors such as increased global competition, sudden changes, the need for quality and after-sales service, limited resources, and so on.they are under much force so after years of experience, the world concludes that if an organization wants to be a leader in its business and economy and not stay behind in the arena of competition, it must have highly skilled, creative and motivated human resources. Human resources form the basis of an organization's real wealth.

it gives empowering potentials to exploit the source of human capacity that is not fully utilized. Capable and purposeful personnel play the most important role in the continuous improvement of organizations and are unique funds for growth and promotion(Haman). Now given the increasing importance of empowerment in achieving organizational goals and its efficiency,in this research, we have tried to study the criteria affecting human resource empowerment ,Then we rank these factors using Topsis method.

\section{1-3-Necessity and importance}

Empowerment is one of the most important topics to consider in the human resources literature. Managers are looking for tools to empower employees in a safe environment and in the areas that provided for them. Empowering is the result of classic management thinking, increasing the productivity of transformation in tools and methods. As a result of relationships among people in terms of job satisfaction, the democratic leadership was addressed. Paying attention to the social needs of staff was considered one of the most important goals. In the past, organizations used dictatorial and authoritarian styles, and this was a way of disenfranchising and decimating of staff. Empowerment has been widespread in the 1990s, although it has been discussed before. In the past, empowerment refers to industrial democracy and the involvement of employees in the decision making of the organization under the titles of teaming, partnership and comprehensive quality management and the latest changes about this subject were called staff empowerment.

\section{1-4-Research objectives}

\section{1-4-1-The main objective}

The main objective of the research is identifying the effective criteria on human resource empowerment and education system and then ranking these factors.

\section{1-4-2-Subsidiary objectives}

-Identifying the most important factor affecting school human resource Empowerment

-Providing solutions and suggestions for improving staff empowerment according to research findings.

\section{1-5-Research Questions}

What are the factors affecting the empowerment of staff of Masjed Soleiman schools?

Which of the factors has the greatest impact on human resource empowerment?

\section{1-6-Research hypotheses}

Providing information is effective on human resource empowerment.

Delegation is effective on staff empowerment.

Team is effective on staff empowerment.

Organizational structure is effective on staff empowerment.

Having clear goals is effective on staff empowerment.

Independence is effective on staff empowerment. 
The reigning system is effective on staff empowerment.

Access to resources is effective on staff empowerment.

Training is effective on staff empowerment.

Performance measurement is effective on staff empowerment.

\section{1-7-Conceptual Model of Research}

In this research, empowerment dimensions are considered based on Spreitzer model (1995) and the conceptual model of research has been shown in Figure 1.

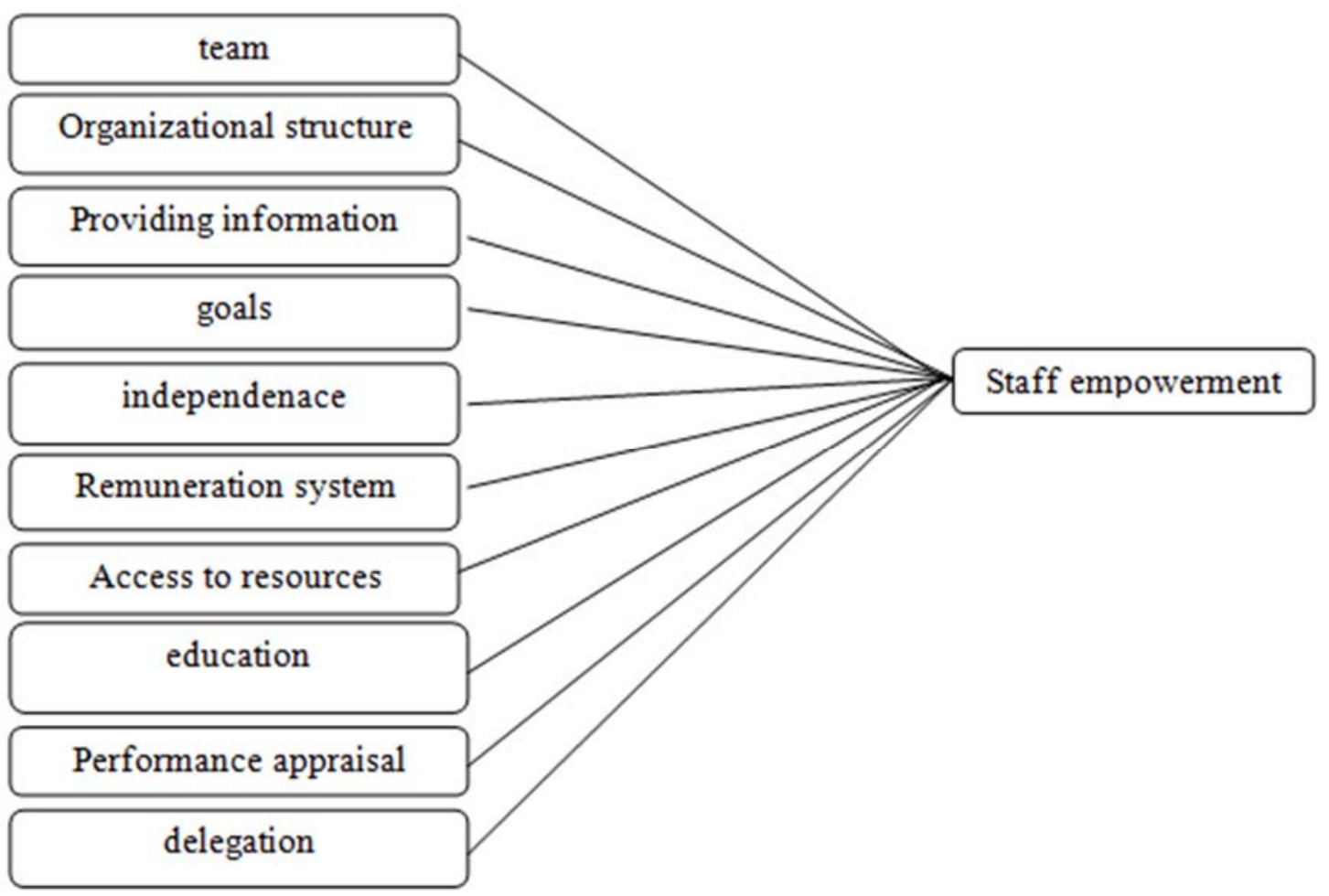

Figure 1-1 The Conceptual Model of Research

\section{1-8-Research Area}

\section{1-8-1-Spatial Area}

The spatial Area of the research is the city schools. The number of staff is 211.

\section{1-8-2-The temporal Area}

This study was conducted from May 2018 to June 2019.

\section{1-8-3-Subject Area}

From the subject perspective, this research generally is within the scope of organizational behavior and human resources, specifically referring to the issue of human resource empowerment, which is discussed fully and separately and its dimensions is defined and we discussed the impact of each dimension.

\section{1-9-Users of research findings}

By presenting solutions and suggestions based on research findings, it can predict that managers and organizational decision makers can understand the role of empowering employees in the organization, by considering the different components and functions and considering these factors in their decisions in the organization, they can facilitate and accelerate the process of improving the level of human resources empowerment and achieving its goals.

In summary, the results of this study can be used by the following groups:

Education managers and education policymakers

Professors, students and humanities researchers

\section{2-Research Background}

Lester Thurow, famous economist in the "Building Wealth" book, considers the amount of intelligence, wisdom and human knowledge,the most important competitive advantage for organizations in the third millennium . He believes that oil and natural resources can no longer be sources of wealth, it is the intelligence and wisdom of 
individuals that can move society to growth.If people want be in this new challenge, they have no choice but to think fully about the role of knowledge and intelligence in the development of their society(Abili,1380).

on the other hand, the purpose of empowerment theories is how to use environmental components, their knowledge, perceptions and individual characteristics to ransfering power to them and transform their potential abilities to applicable (zimer,2008).

By employing the right relationship between these factors, the process of human resource empowerment achieves the goals more quickly and the individual, community and organization better exploite the goals of empowerment.In fact, empowerment theory says that an organization can satisfy its own people while at the same time getting what it needs and that relationship can be a win-win.(scott\&jeff, 2008).

\section{2-2-Empowerment}

Empowerment: In Webster's word culture, the word "Empowerment" is divided into three components:

EM: In the first of name it means putting in, going out, going in.

Power: Allows individuals to persuade others to perform activities or tasks as expected and gives the power holder to inform others from the consequences or action process before they engaging in the action or avoid them from conflict.

Ment: refers to the position or status of a particular action such as starting, completing, expanding, and empowering (Wallerstein, 1992, 197).

The Oxford Dictionary also defines empower verb as empowerment and conditions to improve the motivation of individuals to perform their duties by cultivating a sense of self-sufficiency.

Various researchers have searched the empowerment dimensions with different magnifiers: self-control, authority over jobs, diversity of team work, the performance-related payment system are all called empowerment.

Bennis 1989, Block 1987, Kanter 1977, call empowerment as an approach that the leader empowers his staff as a core component of organizational and managerial effectiveness (Hawland\&Smith,1977).

Job empowerment is a process of empowerment that expands one's feelings of trust and control to herself or himself and to his or her organization. This process is moderated by many cognitive constructs, such as selfesteem and self-efficacy, and may lead to outcomes such as performance and satisfaction. In other words, during the process of empowerment, the change that is usually facilitated by others in the workplace, occurs beyond what one feels. Some scholars extend the concept of empowerment and apply it to any situation that gives individuals the sense of work control, providing the workforce needed to take the initiative and steering them to meaningful work. In Ilen, empowerment is a purely individual and multifaceted motivational force that can be evoked from within the individual, either by colleagues or managers. Here, empowerment is manifested through changes in one's perceptions and in the behaviors of others (Sandra et al., 2014).

empowerment is giving authorization to staff for making decision so as to increase their work effectively in order to play a useful role in the organization (Arstead, 1997).

Empowerment means that employees are able to understand their tasks well before you tell them what to do (Savory \& Lux, 2001).

Empowerment includes removing barriers to growth, encouraging commitment to goals, encouraging risktaking, creativity and innovation, and enabling individuals to solve problems, increase responsibility, and eliminate fear. In short, empowerment is the end of all things that hinder growth, freedom of action, self-esteem, participation and cooperation (Rational and Akbari, 2005, 73). Low-level empowerment refers to a situation where staff encourage to offer, but the manager is not required to implement those suggestions, on the other hand, High-level empowerment involves a situation in which staff believe in their specific tasks and the proper performance of those tasks(Rafic, 1998, 82).

\section{Research steps}

according to two criteria: a) the purpose of the study, b) the way of collecting data.

In this section, the research data is analyzed and evaluated using scientific methods. The purpose of collecting data from the questions and classifying them is to fully understand the variables and their relationships so that they can be summarized and concluded according to the research goals. Analysis of the findings is done in two parts. The first part, collected data are described.At first Descriptive statistics were used to sort the data, based on sorted data, the research data is shown in the relevant tables. The next part of the data analysis is based on statistical inference.The purpose of inferential statistics is concluding about the characteristics of the community from which the sample was extracted. 
In this study, first descriptive analysis of findings and then inferential analysis of findings (research questions test) are examined. In the data description section, frequency, percentage, charts and data analysis and in inferential section regression and Topsis are used, respectively.

\section{Final analysis of factors affecting empowerment}

We draw a table for final analysis based on internal factors(weaknesses and threats )and external factors( opportunities and threats )with 4 columns including factors, weight, rating and weighting. In Column 1( External and internal factors)we write the most important strengths, weaknesses, opportunities, and threats to the system.

In column two (weight), each of these factors and their possible effects on the current strategic position of the system (based on the results of the findings from the analysis and analysis of the status quo) we give weigh from one (most important) to zero (least important). The higher weight, the greater its impact on the current and future position of the system (sum in column 2, regardless of the number of factors, is 1).

In column 3, (rating ), to each factor, and by the system's current status an importance, we give to that particular factor, a score of 5( very good )up to 1 ( poor ), ( based on the results of cognition and current status analysis). This rating shows how the system responds to any external factors.

In column 4(weightings), we multiply the weight by degree of each factor ( column 2 multiplies by column 3 ) to obtain its weight score. Thus, for each factor, a weighted score from 1 to 5 is obtained, which this score number has an average of 3 .

Finally, we sum the weightings of all external and internal factors in column 4 individually and calculate the weighting. The total weighting score shows how a system responds to existing and potential agents and forces in its external environment. The sum weighting average of a system in a given field is always 3.If it is higher than 3 , it has more importance and if it is lower than 3 , it has less importance.

\section{1-3-4-Findings and Multivariate Analysis of Demographic Factors}

In this analysis, we have examined the impact of demographic factors on their empowerment.We have identified the effect of different demographic factors, such as sex, marital status or single on the type of response.

Table 4-6- multi variable regression for predicting staff empowerment by step by step method

\begin{tabular}{|c|c|c|c|c|c|}
\hline Sig & $\mathbf{F}$ & $\mathbf{R}^{\mathbf{2}}$ & $\mathbf{R}$ & variable & row \\
\hline 0.000 & 1775.35 & 0.918 & 0.958 & education & first step \\
\hline 0.000 & 1227.52 & 0.921 & 0.960 & gender & Step Two \\
\hline 0.000 & 1040.50 & 0.930 & 0.964 & Marital status & Step Three \\
\hline 0.000 & 860.82 & 0.932 & 0.965 & age & Step Four \\
\hline 0.000 & 946.36 & 0.948 & 0.974 & Work experience & Step Five \\
\hline
\end{tabular}

Table 4-7 Standard and non-standard regression coefficients

\begin{tabular}{|c|c|c|c|}
\hline Sig ( T ) & T & B & Predictive variable \\
\hline 0.000 & -9.48 & -0.630 & education \\
\hline 0.000 & -5.85 & -0.329 & gender \\
\hline 0.000 & 6.87 & 0.331 & Marital status \\
\hline 0.000 & 10.20 & 0.794 & age \\
\hline 0.000 & -9.71 & -0.805 & Work experience \\
\hline \multicolumn{2}{|c|}{$\mathbf{R}=\mathbf{0 . 9 7 4}$} & & $\mathbf{R}^{2}=\mathbf{0 . 9 4 8}$ \\
\hline
\end{tabular}

Our model has been able to move up to 5 steps, The value of $\mathrm{R}^{2}$ was 0.918 in the first stage, it reached to .0921 in the second stage, and reached to .0930 in the third stage, reached to .0932 in the fourth stage, and finally it reached to 0.948 in the last stage, i.e the regression line equation Using these components, was able to predict $94 \%$ of the effects of the dependent variable.

\section{Path Analysis}

path analysis is one of the most advanced statistical methods that shows how the independent variables affect the dependent variable as well as the independent variables influence each other. This method shows both the direct influence of the independent variables and their indirect effect on the dependent variable through the path coefficients. The path coefficients are the beta or standardized regression coefficients that represent the extent of the net effect of each independent variable on the dependent variable. 
Table4- 8 Calculations the effects of the factors on the dependent variable

\begin{tabular}{|c|c|c|}
\hline Total effect & Direct effect & variable \\
\hline 0.842 & 0.842 & education \\
\hline 0.791 & 0.791 & gender \\
\hline 0.634 & 0.634 & Marital status \\
\hline 0.789 & 0.789 & age \\
\hline 0.798 & 0.789 & Work experience \\
\hline
\end{tabular}

The table above shows the direct and total effect of the factors on the dependent variable of the research. Most impact on empowerment variable of staff is the variable of education with 0.842 and the least impact is the variable of marital status with 0.634 on the variable of staff empowerment. In general, the direct effect of education variable was 0.842 , gender variable 0.791 , marital status 0.634 , age variable 0.789 and work experience variable was 0.798 .

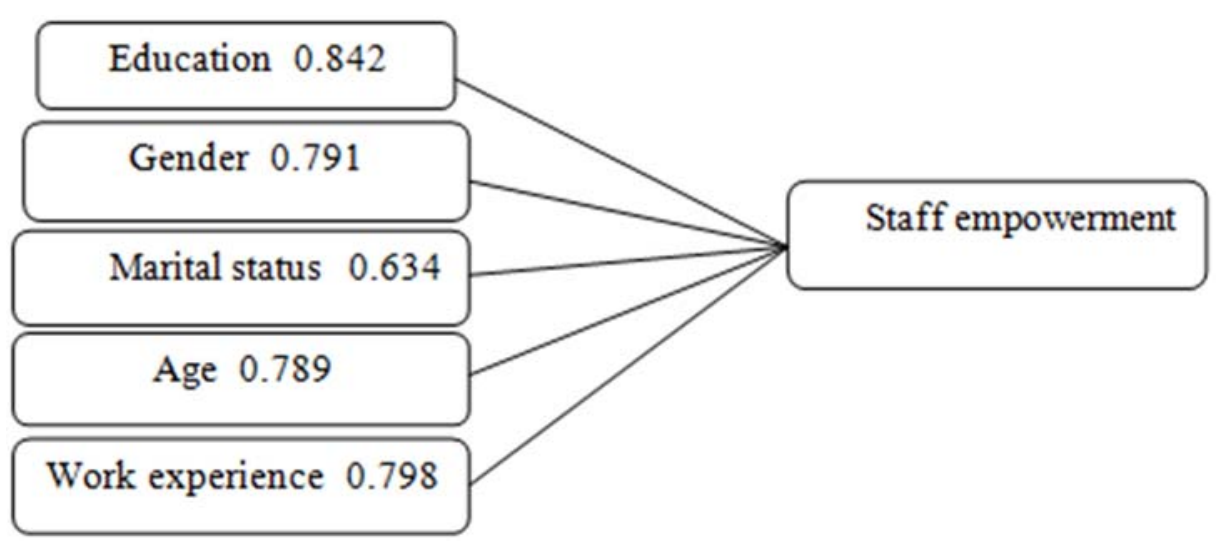

Figure 4-1 path Analysis Model

Analyzing the relationships between variables(research hypotheses test)

In this section Regarding the nature of the hypotheses presented in this study, regression is used. Hypothesis 1:

$\mathrm{H}_{0}=$ Providing information is not effective on empowerment.

$\mathrm{H}_{1}=$ Providing information is effective on empowerment.

Table 4-9 Correlation Coefficient to Investigate the Impact of Providing Information on Empowerment

\begin{tabular}{|c|c|c|c|}
\hline Providing information & empowerment & \multicolumn{2}{|c|}{ variable } \\
\hline $\begin{array}{c}1 \\
75\end{array}$ & $\begin{array}{c}0.777 \\
.000 \\
75\end{array}$ & $\begin{array}{c}\text { Correlation Coefficient } \\
\text { confidence level sig } \\
\text { number }\end{array}$ & Providing information \\
\hline $\begin{array}{c}0.777 \\
.000 \\
75\end{array}$ & $\begin{array}{c}1 \\
75\end{array}$ & $\begin{array}{c}\text { Correlation Coefficient } \\
\text { confidence level sig } \\
\text { number }\end{array}$ & empowerment \\
\hline
\end{tabular}

The output of the relevant statistical calculations using the Pearson test sig.00 At $99 \%$ confidence level, the significant relationship between the above two variables is statistically confirmed.

Therefore, providing information is effective on empowerment.

Hypothesis 2:

$\mathrm{H}_{0}=$ Delegation does not affect empowerment.

$\mathrm{H}_{1}=$ Delegation is effective on empowerment. 
Table 4-10 Correlation Coefficient to Study the Impact of Delegation on Empowerment

\begin{tabular}{|c|c|c|c|}
\hline Delegation & empowerment & \multicolumn{2}{|c|}{ variable } \\
\hline 1 & .646 & Correlation Coefficient & Delegation \\
& .000 & confidence level sig & \\
75 & 75 & number & \\
\hline .646 & 1 & Correlation Coefficient & empowerment \\
.000 & & confidence level sig & \\
75 & 75 & number & \\
\hline
\end{tabular}

The output of the relevant statistical calculations using the Pearson test sig.00 At 99\% confidence level, the significant relationship between the above two variables is statistically confirmed. therefore Delegation is effective on empowering staff.

Hypothesis 3:

$\mathrm{H}_{0}=$ Team does not affect empowerment.

$\mathrm{H}_{1}=$ Team is effective on empowerment.

Table 4-11Correlation Coefficient to Investigate the Impact of Team on Empowerment

\begin{tabular}{|c|c|c|c|}
\hline Team & Empowerment & varial & \\
\hline $\begin{array}{c}1 \\
75 \\
\end{array}$ & $\begin{array}{c}.825 \\
.000 \\
75 \\
\end{array}$ & $\begin{array}{c}\text { Correlation Coefficient } \\
\text { confidence level sig } \\
\text { number }\end{array}$ & Team \\
\hline $\begin{array}{c}.825 \\
.000 \\
75\end{array}$ & 1 & $\begin{array}{l}\text { Correlation Coefficient } \\
\text { confidence level sig } \\
\text { number }\end{array}$ & Empowerment \\
\hline
\end{tabular}

The output of the relevant statistical calculations using the Pearson test sig.00 At 99\% confidence level, the significant relationship between the above two variables is statistically confirmed.

Thus Team is effective is effective on empowerment.

\section{Effective Internal Factor Analysis Results(IFAS)}

To organize the internal factors in terms of the strengths and weaknesses of the system, using the rating factors and considering the importance of each of the strengths and weaknesses, and considering the impact of each of them(Ebrahimzadeh and Aghassizadeh, 1388,117) on the functions of the Iranian economy, they calculated and determined as follows in Table 1:

Table 1 Results of the analysis of internal factors (Strengths)

\begin{tabular}{|c|c|c|c|}
\hline Weight Score & Rating & Weight & Strengths \\
\hline 0.72 & 4 & 0.18 & Management attitude towards empowerment \\
\hline 0.68 & 4 & 0.17 & Staff willingness to learn and improve \\
\hline 0.24 & 4 & 0.08 & In-service programs and courses \\
\hline 0.27 & 3 & 0.09 & Leadership and management style \\
\hline 0.27 & 3 & 0.09 & The importance of learning in the organization \\
\hline 0.07 & 1 & 0.07 & Provide learning opportunities \\
\hline 0.07 & 1 & 0.07 & the trust and companionship of the staff \\
\hline 0.16 & 2 & 0.08 & Physical facilities in schools \\
\hline 0.27 & 3 & 0.09 & Organizational structure transparency \\
\hline 0.27 & 3 & 0.09 & Number of computers available \\
\hline 3.03 & & 1 & sum \\
\hline
\end{tabular}


Table 2 Results of the analysis of internal factors (weaknesses)

\begin{tabular}{|c|c|c|c|}
\hline Weight Score & Rating & Weight & Weaknesses \\
\hline $0 / 60$ & 4 & $0 / 15$ & Lack of transparency of organizational goals \\
\hline $0 / 44$ & 4 & $0 / 11$ & Inappropriate gender distribution status \\
\hline $0 / 48$ & 4 & $0 / 12$ & Unrelated field of education and expertise to job \\
\hline $0 / 20$ & 2 & $0 / 10$ & Inappropriate staff recruitment status \\
\hline $0 / 52$ & 4 & $0 / 13$ & dissatisfaction Employees about their salary \\
\hline $0 / 44$ & 4 & $0 / 11$ & Lack of staff welfare plans \\
\hline $0 / 21$ & 3 & $0 / 07$ & the way of hiring \\
\hline $0 / 27$ & 3 & $0 / 09$ & Collaboration among employees \\
\hline $0 / 10$ & 2 & $0 / 05$ & credits in the field of human resources \\
\hline 3 & & 1 & sum \\
\hline
\end{tabular}

\section{External Factor Analysis Results (EFAS)}

To organize external factors in terms of opportunities and threats facing the system, using rating factors and considering the importance of each opportunity and threat and considering the extent to which each of them has an impact on empowerment functions, calculate and was determined as following table:

Table 3 External Factor Analysis Results (Opportunities)

\begin{tabular}{|c|c|c|c|}
\hline Weight Score & Rating & Weight & Opportunities \\
\hline 0.64 & 4 & 0.16 & Cultural conditions in society \\
\hline 0.44 & 4 & 0.11 & The capacity to adaption and implement innovation \\
\hline 0.48 & 4 & 0.12 & Education level of individuals \\
\hline 0.07 & 1 & 0.07 & Level of communication with educational centers \\
\hline 0.3 & 3 & 0.1 & Talent Recognition System \\
\hline 0.27 & 3 & 0.09 & Letters and numerous human resources guidelines \\
\hline 3.01 & & 1 & sum \\
\hline
\end{tabular}

Table 4 presents the results of the analysis of the threat points by weight as well as its weighting score.

Table 4 External Factor Analysis Results (Threats)

\begin{tabular}{|c|c|c|c|}
\hline Weight Score & Rating & Weight & Threats \\
\hline 0.54 & 4 & 0.14 & Economic conditions in society \\
\hline 0.27 & 3 & 0.09 & The pace of technology and science change \\
\hline 0.27 & 3 & 0.09 & Employment and Promotion Laws \\
\hline 0.27 & 3 & 0.09 & Involvement of other government agencies \\
\hline 0.52 & 4 & 0.13 & Low level of education \\
\hline 0.16 & 2 & 0.08 & Credits and Expenses of the Organization to Empower Personnel \\
\hline 0.24 & 3 & 0.08 & Involvement of other government organization \\
\hline 3.03 & & 1 & sum \\
\hline
\end{tabular}

\section{Analysis of strategic factors}

In this model using the tables of internal and external factors analysis and their combination 'the most important strategic factors in educational deprivation are presented. In fact, by analyzing strategic factors, planners who make strategic decisions can limit the strengths, weaknesses, threats, and opportunities to a smaller number of factors. This is done by re-examining the weights of each of the factors in the internal and external factor analysis tables. In fact, the heaviest factors in these two tables by weight should be transferred to 
the strategic factor analysis table (Hanger \& Violin, 2007, pp. 130-127). This is summarized in the following table regarding the influencing strategic factors:

Table5-Analysis of strategic factors (SFAS)

\begin{tabular}{|c|c|c|c|c|c|c|}
\hline \multicolumn{3}{|c|}{ Planing } & \multirow{2}{*}{$\begin{array}{l}\text { Weight } \\
\text { Score }\end{array}$} & \multirow[t]{2}{*}{ Rating } & \multirow[t]{2}{*}{ Weight } & \multirow[t]{2}{*}{ Factors } \\
\hline Long time & $\begin{array}{c}\text { Mean } \\
\text { time }\end{array}$ & $\begin{array}{r}\text { Short } \\
\text { time }\end{array}$ & & & & \\
\hline * & * & & 0.72 & 4 & 0.18 & S1 Management attitude towards empowerment \\
\hline * & & * & 0.68 & 4 & 0.17 & S2 Staff willingness to learn and improve \\
\hline & & * & 0.27 & 4 & 0.09 & S3 In-service programs and courses \\
\hline * & & * & 0.27 & 3 & 0.09 & S4 Leadership and management style \\
\hline * & & * & 0.27 & 3 & 0.09 & S5 The importance of learning in the organization \\
\hline * & * & & 0.27 & 3 & 0.09 & S6 Provide learning opportunities \\
\hline & & * & 0.36 & 4 & 0.09 & W1 Inappropriate gender distribution status \\
\hline & & * & 0.32 & 4 & 0.08 & W2 Unrelated field of education and expertise to job \\
\hline & & * & 0.32 & 4 & 0.08 & W3 Inappropriate staff recruitment status \\
\hline * & * & & 0.28 & 4 & 0.07 & W4 dissatisfaction Employees about their salary \\
\hline & & * & 0.28 & 4 & 0.07 & W5 Lack of staff welfare plans \\
\hline * & & * & 0.64 & 4 & 0.16 & O1 Education level of individuals \\
\hline * & & * & 0.48 & 4 & 0.12 & O2 Level of communication with educational centers \\
\hline & & * & 0.44 & 4 & 0.11 & O3 Talent Recognition System \\
\hline & & * & 0.44 & 4 & 0.11 & O4 Letters and numerous human resources guidelines \\
\hline & & * & 0.54 & 4 & 0.14 & T1 Economic conditions in society \\
\hline * & & * & 0.52 & 4 & 0.13 & $\begin{array}{l}\text { T2 Applying Communication Influences in the } \\
\text { Organization on the Issue of Recruitment and } \\
\text { Employment }\end{array}$ \\
\hline * & & * & 0.36 & 3 & 0.12 & $\begin{array}{l}\text { T3 Credits and Expenses of the Organization to } \\
\text { Empower Personnel }\end{array}$ \\
\hline * & & * & 0.33 & 3 & 0.11 & T4 Involvement of other government organization \\
\hline
\end{tabular}

Now by interfering these factors with each other, we develop different competitive /offensive strategies (so), diversity (st), revision (wo) and finally defensive (wt) strategies (Behzadfar \& Zamani, 2008, 100)that are in the following :

formulation Strategies

Competitive / Offensive Strategies (so)

In these strategies, the focus is on internal strengths and external opportunities, which include:

Creating a fit between staff training courses and career goals and objectives;

Using appropriate internal organizational capacity to increase staff turnover;

The most appropriate exploitation of the talent identification system, workforce;

Diversity strategies (st) In Diversity the focus is on a variety of internal strengths and external threats, including: Use of all internal capacities in the formulation of job promotion and the use of committed managers;

Develop and diversify staff training programs to meet the needs of teachers in order to enhance the quality of teaching and combat negative advertising in the field;

Designing and deploying organizational structure to improve teacher activities, educational deprivation;

Review Strategies (wo)

Emphasizing on internal weaknesses, it seeks to take advantage of external opportunities to overcome the weaknesses beyond the empowerment of staff, including: 
Using Talent Identification Systems to Establish Decency Promote a participatory management culture in decision-making in organizational affairs Use of human resources related regulations;

Defensive Strategies (wt)

These strategies emphasize on the ability to fix vulnerabilities of empowerment, including:

Striving to increase staff productivity, Developing programs to alleviate employees' economic problems; Equitable distribution of amenities and rights and benefits to improve the standard of living of personnel;

\section{Research Results}

Hypothesis 1: Providing information is effective on human resource empowerment. The output of the relevant statistical calculations using the Pearson test sig.00 At 99\% confidence level, the significant relationship between the above two variables is statistically confirmed. Because sig $<0.01$, so providing information is effective on human resource empowerment. The results of this study are along with the results of Diane Tracy, Weyk, Nunak and Jane Smith. Diane Tracy believed that leaders must be very careful about giving information. The information provided to people should be able to give a true picture of the organization. Information refinement reduces the trust and credibility of accurate information, that is it has to say anything which is exist, no less and no more, to empowerment employees. (Diane Tracy, Bita). According to Wick, access to information will increase people's understanding of complex problems. Nunak also believed that information exchange is an important component of the independence of action and ultimately person empowerment. (Spreizer, 1996).

Jane Smith also considers sharing information between people, one of the factors contributing to the development of people's independence. He emphasizes that information, facilitates decision making .If we don't share information among staff, we cannot expect them to accept responsibility, without information we cannot decide and implement. If we give people information, we are not helping them but giving them responsibility and empowering them (Jane Smith, 2000).

Hypothesis 2: delegation is effective on staff empowerment.

The output of the relevant statistical calculations using the Pearson test sig.99 At $99 \%$ confidence level, the significant relationship between the above two variables is statistically confirmed. Because sig $<0.01$ so delegation is effective on human resource empowerment. The results of this study are along with the results of Schul et al. and Kanter. From the perspective of the communication approach, empowerment is the process by which a leader or manager attempts to divide his or her power between his inferiors(Conger\&Kanungo,1998). According to Cantor, empowerment is based on transferring of autorities and responsibility (Kanter, 1983). Schul and his colleagues believe that empowerment is about giving employees more authority to make the decisions they need without first getting approval from higher-level officials.

Hypothesis 3: Team is effective on staff empowerment.

The output of the relevant statistical calculations using the Pearson test sig.00 At $99 \%$ confidence level, the significant relationship between the above two variables is statistically confirmed. Because sig $<0.01$, so team is effective on human resource empowerment. The role of teams in empowerment is crucial because it is the source of diverse ideas and experiences to deal with the complex problems that organizations face in a changing and competitive business world. Group awareness is far more than any individual's awareness. It should be noted that no one alone is as intelligent as all in the team. On the other hand, the group's ability is greater than the algebraic sum of the individuals' ability, because it is $1+1=2$ regarding the principle of synergy. That is why the team is the source of attractive ways that can open the door to major production, quality, service and financial problems. In addition, just as a group of people can move heavy loads, cross members from barriers, or work together to solve individual problems, in organizations, the team can solved complex solution, too (amini,bita).

\section{References}

[1] Abadi Farahani, Majid, 2005, Investigating the Relationship between Organizational Structure and Empowerment of Staff, MSc thesis, Administration, University of Tehran.

[2] Azarnia, Mohammad Ali, 2008, Empowering Employees, Key to Increasing Productivity, Sarmayeh Newspaper, No. 810.

[3] Armstrong, Michael, 2007, Translated by Abolfazl, Human Resource Management in Action, Sohrabi Publications.

[4] Aghiar, Sirous, 2003, Empowering a New Approach in Competitive Environment, Monthly,. Tadbir, No. 135.

[5] Harabadi Farahani, Majid, (2005), Investigating the Relationship between Organizational Structure and Personnel Empowerment, Thesis, Tehran, University of Tehran.

[6] Hassanzadeh, Mohammad Sadegh, (2004), Investigating the Impact of Organizational Culture on Empowering Personnel of Active Car Companies, Thesis, Tehran, Tarbiat Modarres University.

[7] Khaki, Gholamreza, 2000, Management Research Method, Tehran, Islamic Azad University Press Center.

[8] Sinita, Scott, 1999, Translated by: Dr. Mahdi Iran, Personnel Empowerment Management.

[9] Salehi Zadeh, Saeed, 2006, Human Resources Empowerment in Government Organizations, Islamic Azad University, Khorasgan Branch.

[10] Taheri Tariq, Soodabeh, (2004), Investigating the Role and Position of Empowerment of Personnel on Performance of Tehran Refah Bank, Thesis, Tehran, Shahid Beheshti University. 
[11] Gholami Nasrin, Bita,2006, Empowerment of Employees, Skills Monthly, No. 52, pp. 12-15.

[12] Mohammadzadeh Taheri, Hanieh, (2005), Investigating the Factors Affecting Empowerment of Personnel in Social Security Organization, Thesis, Payame Noor University, Tehran.

[13] Mohammadi, Mohammad, 2002, Staff Empowerment Programs, Studies Journal, Publication: Allameh Tabatabai University. Management, No. 36

[14] Mazid Abadi Farahani, Amir Hossein, (2004), Investigating the Effects of Information Technology Application on Personnel Empowerment ", A Study in the Social Security Organization of Qom" Thesis, Tehran University, Tehran.

[15] Yari, Hamid Reza, (2006), A Study on the Status and Requirements of Human Resources Empowerment in Hamadan Governorate, Thesis, Azad University of Boroujerd.

[16] Ahmadi, Samira, 2006, Investigating the Relationship of Emotional Intelligence with Empowering the Staff of Isfahan General Directorate of Sport and Youth, 6th Iranian Scientific Conference on Educational and Psychological Sciences, Social and Cultural Injuries, Tehran, Association for Development of Fundamental Sciences and Technologies, https : //www.civilica.com/PaperPSCONF06-PSCONF06 166.html.

[17] Darvishi, Iran, 2006, Investigating the Relationship of Spiritual Orientation on the Empowerment of High School Teachers in Neka, 6th Conference of Educational and Psychological Sciences, Social and Cultural Damage of Iran, Tehran, Association for Development and Promotion of Fundamental Sciences and Technologies, https: / /www.civilica.com/Paper-PSCONF06-PSCONF06 201.html.

[18] Razavi, Mohammad reza and Yousef Gholipourkanani, 2008, Presentation of Knowledge Management Model among the Employees of Iran Marine Industry Company (Sadra), Journal of Applied Research in Engineering 2 (8), https://www.civilica.com/ PaperJR_ARTE-JR_ARTE-2-8_013.html.

[19] Bagher Salimi, Saeed and Hossein Dashmir, 2006, The Impact of Electronic Readiness on Job Empowerment of Government Employees (Case Study: Guilan Provincial Governors and Subsidiaries), New Research in Management and Accounting 4 (11), https: // www.civilica.com/Paper-JR_JRMA-JR_JRMA-4-11_012.html.

[20] Amiri, Reza and Bahman Mashmeli, 2000, Investigating the Relationship between Intellectual Capital and Employee Performance with regard to the Mediating Role of Empowering Employees of Reliance Chain Stores North of Iran, Third Conference on Community Empowerment in Humanities and Psychological Studies, Tehran, Iran. Community Cultural and Social Skills Empowerment, https://www.civilica.com/Paper-PECONF03-PECONF03_108.html.

[21] Jalali, Ramin, Seyyed Mahdi Alvani, Akbar Hassanpour and Yousef Mohebzadegan, 2006, Identification and Modeling of Factors Affecting Empowerment of Maritime Managers, Quarterly Journal of Marine Science Education 4 (1), https: //www.civilica.com/Paper-JR_MST-JR_MST-4-1_002.html.

[22] Rasouli, Eshagh; Seyed Mojtaba Fatemi; Seyed Asghar Saadati and Keyvan Ouchi, 2006, Investigating the Impact of Job Challenge Stressors on Empowering Academic Members of Ardabil Islamic Azad University, 2nd International Congress and Third Conference on Community Empowerment and Humanities Educational Studies, Tehran, Community Center for Cultural and Social Skills Empowerment, https://www.civilica.com/Paper-BSLH03-BSLH03 021.html.

[23] Bahari, Masoud and Mojgan Radmanesh, 2017, Investigating the Role of Organizational Factors in Human Resources Empowerment of Bushehr Port Authority Maritime Administration, International Conference on Management, Accounting, Banking and Economics in Horizon Iran 1404, Mashhad, Https://www.civilica.com/Paper-MABECONF01-MABECONF01.

[24] Nourbakhsh, Mahvash; Shadi Leader Yaghoubi and Mehdi Kohandel, 2011, The Relationship between Transformational Leadership Style and Organizational Commitment with Psychological Empowerment of Male and Female Employees of Alborz Provincial Office of Sport and Youth, Fourth National Conference on Sport Science and Physical Education, Tehran,: Society for the Advancement of Fundamental Science and Technology, https://www.civilica.com/Paper-SPORTCONF04-SPORTCONF04 045.html.

[25] Talebi Fard, Roqieh, and Mahnoush Abedini, 2009, Investigating the Relationship between Spiritual Intelligence and Empowerment of Anvar Women Supported by Imam Khomeini Relief Committee, New Research in Humanities 3 (20), https://www.civilica .com / Paper-JR JHSR-JR JHSR-3-20 008.html.

[26] Argyris, Chris, May-Jun.,(1998). Empowerment the Emperors New Clothes, Harvard Business Review.

[27] Blanchard, K. H \& Carlos, J.P and Randolph, A.(2003). Empowerment Take More Than One Minute, Barrett-Koehler. Sanfrancisco

[28] Bowen, D. E \& Lawler, E.E. (1992). the Empowerment of Service Workers. What, Why, Who, When, Sloan Management Review

[29] Bodner, sara(.2003). Dimensional assessment of empowerment in organization. Unpolished Doctorial Dissertation.University of north texas.

[30] Bowen D. E, Lawler EL.( 1995). Empowering service employees. AMR; 19(3): 21-31.

[31] Cartwrith Roger. (2002). Empowerment, Easton publishing.

[32] Conger, J.A, kanungo, R.W. (1998). The empowerment process: integrating theory and practice, Academy of management reviw, 13 471-482

[33] Erstad Margaret. (1997). Empowerment \& Organizational Change. International Journal of Contemporary Hospitality Management: MCB. University Press.

[34] Erich A., Mar .(1999). Antecedents \& Out Comes of Empowerment; Group \& Organization Management, Vol.34, Issue.1.

[35] GAO. (2001). Human Resource management in The Hospitality Industry, Wiley Koberg Christine S, Boss R. Wayme, Senjem Janson C. \& Goodman

[36] Greasley, kay.Bryman, A, Dainty, A, soetanto, R \&Nicolu, king. (2005). Employee perceptions of empowerment" employee relations, 27/4:354-368

[37] Greadey.(2007). kay, Bryman, A. Dainty, A. , Price,A. Naismith, A. ,\&soctanto, R. 2007 "Understanding empowerment form employee perspective: what does it mean \& do they want it?" team performance management. $1 \mathrm{H} / 2: 39-55$.

[38] HonoldLinda, (1997). "Are view of literature on employee empowerment" empowerment in organization, 5/4 202-212.

[39] Koontz, H., Weihrich, H. (1995). Essentials of management. New York.

[40] Lee Hyun-Jung. (2004), "The role of competence-based trust and organizational identification in continuous improvement", Journal of Management Psychology, Vol.19, No.6, PP.623-639.

[41] Maccoby Michel. (1999). Re-Thinking Empowerment.

[42] Mc Lagan, P. \& Nel, C. (1997). The Age of Participation: New Governance for the Workplace \& the World, edition.2. Beret Koehler Sanfrancisco, CA.

[43] McGrawHill Quinne. R. E \& Speritzer. G. M. (1997).“The road to empowerment: seven questions every leader should consider", Organizational dynamics, Vol.2, P 26.

[44] Mishra, A.K., and Spreitzer, G.M. (1998). Explaining how survivors respond to downsizing : The role of trust, empowerment, justice, and work redesign. Academy of Management Review, vol. 23, no. 3, pp. 567-588.

[45] Nykodym, N, simonehi, R. \& welling Barbara .(1994). "Employee empowerment" jornal of empowerment in organization 2/3, $45-$ 53. 
[46] Perez, Isabel (2002). the effect of empowerment on organizational effectiveness moderated by leadership style. An applied assessment "A Dissertation presented in partial fulfillment of the requirement for the degree Doctor of philosophy, Alliant international university.

[47] Rafiq Mohammed, Pervaiz.k. Ahmed. (1998); “A contingency Model For Empowering Custo er-contact Servicies Employees”; Management Decision ; Vol. 36; No.10; PP.683-693

[48] Robbins T. L, Crino M. D, Fredendal L.D.(2002).An Integrative Model of the Empowerment Process, Human Resource Management Review.Vol.12.

[49] Roy H. Matthew and Dugal S. Sanjiv .(1998). "Developing Trust: the importance of cognitive flexibility and co-operative contexts", Management Decision, Vol.36, No.9, PP.561-567.

[50] Savery K. Law Son, J. Alan Luks. (2001). The Relationship Between Empowerment, Job Satisfaction \& Reported Stress Levels some Australian Evidence Leadership \& Organization Development, Journal MCB University Press.

[51] Siegall, Marc \& Gardner. Susan. (2000). "Contextual factors of psychological empowerment", California state university, chico, california, USA, Personnel review, Vol. 29, No. 6, PP 703-722.

[52] spreitzer, G.M. (1995). individval empowerment in the work plce: Dimension, measurement,and validation, academy of management journal, 38:1442-1465

[53] Thomas, h.w. \& velthouse, B.A. (1990). cognitive elements of empowerment An "interpretive" model of intrinsic task motivation, academy of management reviw, 15: 666-681

[54] Thomas Kenneth, W \& Velthouse, Betty. A. (1990). Cognitive Elements of Empowerment: An Interpretive Model of Intrinsic Task Motivation, Academy of Management Review. Vol.15. No.4. pp. 666-681

[55] Kim, M., Beehr, T. A., \& Prewett, M. S. (2018). Employee responses to empowering leadership: A meta-analysis. Journal of Leadership \& Organizational Studies, 25(3), 257-276.

[56] Freeman, E. R., Civera, C., Cortese, D., \& Fiandrino, S. (2018). Strategising stakeholder empowerment for effective co-management within fishery-based commons. British Food Journal, 120(11), 2631-2644.

[57] Mone, E. M., \& London, M. (2018). Employee engagement through effective performance management: A practical guide for managers. Routledge.

[58] Adiat, K. O., \& Akintayo, D. I. (2018). Human resource development for sustainable development: Perspective for youth empowerment in Nigeria. IJAME. 